\title{
New Myocardial Infarction by ECG Finding
}

National Cancer Institute

\section{Source}

National Cancer Institute. New Myocardial Infarction by ECG Finding. NCI Thesaurus.

Code C102731.

An electrocardiographic finding of pathologic Q waves, which is suggestive of myocardial infarction of one or more regions of the heart and which is new compared to prior ECGs. No specification is provided for localization. (CDISC) 